\title{
Is Intraperitoneal Chemotherapy After Cytoreductive Surgery Efficient? Knowing Whether It Is or Not Appears Secondary!
}

\author{
Dominique Elias, MD, PhD \\ Department of Surgical Oncology, Gustave Roussy Institute, Villejuif, France
}

The concept of treating peritoneal carcinomatosis (PC) with a curative intent by combining complete cytoreductive surgery (CCRS) resecting all visible disease plus hyperthermic intraperitoneal chemotherapy (HIPEC) or early postoperative intraperitoneal chemotherapy (EPIC) to eradicate the remaining nonvisible disease is logical and seems to be efficient. Described for the first time for 1 patient in 1980 by Spratt et al., it was extensively developed by Sugarbaker et al. during the following years. ${ }^{1,2}$

At the present time, numerous publications consider that this curative combined approach is efficient, mainly for the treatment of peritoneal pseudomyxomas, malignant mesotheliomas, and colorectal PC. ${ }^{3-6}$

However, if you examine all the current data in the literature, an important question subsists: What is the specific role of HIPEC itself in this "package"?

A few randomized experimental trials in animals clearly consider that IP chemotherapy after CCRS exerts a positive impact, but they are limited by 2 weak points: the wide variability of the procedures tested and the difficulty of transposing the results of experimental procedures to humans.

Finally, we have numerous, nonrandomized studies that enable us to attempt to evaluate whether IP alone, with or without hyperthermia, can efficiently cure nonvisible disease. Now, these data are currently astonishing and lead us to wonder about the role of IP chemotherapy following CCRS.

\section{IF WE FOCUS ON COLORECTAL PC}

When we compare HIPEC and EPIC, for the 523 patients in the retrospective French report, median survival

(C) Society of Surgical Oncology 2011

Published Online: 9 July 2011

D. Elias, MD, PhD

e-mail: elias@igr.fr was 31 months for those treated with HIPEC and 32 months for those treated with EPIC. ${ }^{6}$ Sugarbaker and da Silva obtained the same median survival of 33 months for his patients treated with HIPEC or EPIC. ${ }^{7}$

Theoretically, during HIPEC, the open (coliseum) technique is superior in terms of thermal homogeneity and spatial diffusion to the technique with a closed abdomen. ${ }^{8}$ However, when we compare the open (coliseum) technique (HIPEC) and the closed abdomen technique, median survival was not very different with the open technique (31 months, 263 patients) versus the closed technique (29 months, 144 patients in the French report) (unpublished data). ${ }^{6}$ Again, no difference was observed in the results of a team using the closed abdomen technique (median survival of 42.9 months for the 59 cases treated by Verwaal et al.) and those of 2 teams using the open technique (41 months for the 146 patients treated by Quenet et al.).9,10

When different drugs used during HIPEC were compared, no difference was found between patients treated with mitomycin $\mathrm{C}$ and those treated with oxaliplatin in the French report. ${ }^{6}$ Similarly, no difference was found between the patients treated with oxaliplatin alone and those treated with oxaliplatin + irinotecan in the study by Quenet et al. ${ }^{10}$

Also, when the different temperatures and the different durations used during HIPEC were compared, even if the teams used other uncomparable parameters, there was no obvious superiority of high temperatures $\left(42-44^{\circ} \mathrm{C}\right)$ over low temperatures $\left(40-41^{\circ} \mathrm{C}\right)$, nor was there superiority of a long duration ( $\geq 60 \mathrm{~min}$ ) over a short duration ( $<60 \mathrm{~min}$ ).

The main conclusions that can be drawn from these data should be that IP chemotherapy is bereft of efficacy because the results are identical whatever the modalities used. In fact, only a randomized trial in humans comparing HIPEC versus no HIPEC after CCRS will be able to provide a clear conclusion. Such a multicentric randomized trial is ongoing in France (Prodige 7 trial) and has already randomized half of the 260 patients planned for accrual. 
In truth, whatever the result of this trial, confirming or refuting the efficacy of IP chemotherapy in treating nonvisible malignant disease, the concept of wanting to and being able to treat occult residual disease will have played a major role in therapeutic progress. Indeed, all the past and present trials concerning the combination of CCRS plus IP chemotherapy allow us to underline the major prognostic impact of the completeness of cytoreductive surgery on the survival rate. This will continue to be considered major progress and the lesson learned from this concept of combined therapy.

Now, the main reason that encouraged surgeons to devote a lot of time and a lot of energy to resecting all visible malignant disease was this strong belief in the efficacy of combining IP chemotherapy to treat the remaining nonvisible disease.

In the future, if we prove that IP chemotherapy is efficient, it will be a great satisfaction to all the teams who have devoted almost 20 years to using it and to studying it. If we prove that IP chemotherapy is not useful, it will be abandoned, but this concept will have played a major role in motivating surgeons to perform totally complete cytoreductive surgery. In any case, this collateral effect of the concept of using a combined approach to treat PC is and will remain positive.

\section{REFERENCES}

1. Spratt JS, Adcock RA, Muskovin M, Sherril W, Mc Keown J. Clinical delivery system for intraperitoneal hyperthermic chemotherapy. Cancer Res. 1980;40:256-60.
2. Sugarbaker PH, Graves T, DeBruijn EA, Cunliffe WJ, Mullins RE, Hull WE, et al. Early postoperative intraperitoneal chemotherapy as an adjuvant therapy to surgery for peritoneal carcinomatosis from gastrointestinal cancer: Pharmacologic studies. Cancer Res. 1990;50:5790-4.

3. Sugarbaker PH, Chang D. Result of treatment of 385 patients with peritoneal surface spread of appendiceal malignancy. Ann Surg Oncol. 1999;6:727-31.

4. Yan TD, Black D, Savady R, Sugarbaker PH. A systematic review on the efficacy of cytoreductive surgery and perioperative intraperitoneal chemotherapy for pseudomyxoma peritonei. Ann Surg Oncol. 2007;14:484-92.

5. Yan TD, Deraco M, Baratti D, Kusamara S, Elias D, Glehen O, et al. Cytoreductive surgery and hyperthermic intraperitoneal chemotherapy for malignant peritoneal mesothelioma: multiinstitutional experience. J Clin Oncol. 2009;27:6237-42.

6. Elias D, Gilly F, Boutitie F, Quenet F, Bereder JM, Mansvelt B, et al. Peritoneal colorectal carcinomatosis treated with surgery and perioperative intraperitoneal chemotherapy: retrospective analysis of 523 patients from a multicentric French study. J Clin Oncol. 2010;28:63-8.

7. da Silva RG, Sugarbaker PH. Analysis of prognostic factors in seventy patients having a complete cytoreduction plus perioperative intraperitoneal chemotherapy for carcinomatosis from colorectal cancer; J Am Coll Surg. 2006;203:878-86.

8. Elias D, Antoun S, Goharin A, El Otmany A, Puizillout JM, Lasser PH. Research on the best chemohyperthermia technique for treatment of peritoneal carcinomatosis after complete resection. Int J Surg Invest. 2000;1:431-9.

9. Verwaal V, van Ruth S, Witkamp A, Boot H, van Slooten G, Zoetmulder FAN. Long-term survival of peritoneal carcinomatosis of colorectal origin. Ann Surg Oncol. 2005;12:65-71.

10. Quenet F, Goéré D, Mehta S, Roca L, Dumont F, Essissen M, et al. Results of two bi-institutional prospective studies using intraperitoneal oxaliplatin with and without irinotecan during HIPEC following cytoreductive surgery for colorectal carcinomatosis. Ann Surg. 2011 (in press). 